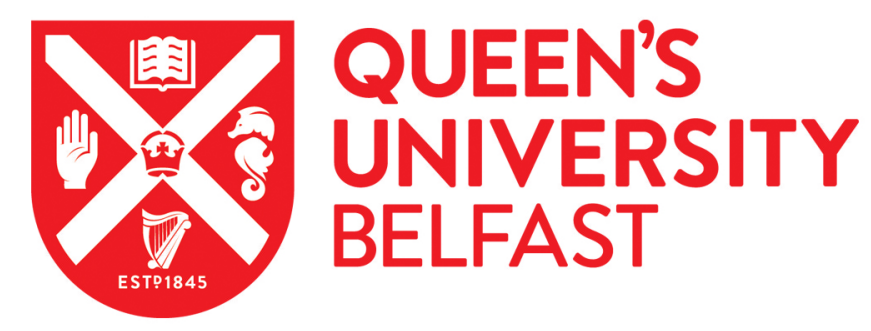

\title{
Title: what about my voice? Autistic young girls' experiences of mainstream school
}

Goodall, C., \& MacKenzie, A. (2019). Title: what about my voice? Autistic young girls' experiences of mainstream school. European Journal of Special Needs Education, 34(4), 499-513.

https://doi.org/10.1080/08856257.2018.1553138

\section{Published in:}

European Journal of Special Needs Education

\section{Document Version:}

Peer reviewed version

\section{Queen's University Belfast - Research Portal:}

Link to publication record in Queen's University Belfast Research Portal

\section{Publisher rights}

Copyright 2018 Taylor and Francis. This work is made available online in accordance with the publisher's policies. Please refer to any applicable terms of use of the publisher.

\section{General rights}

Copyright for the publications made accessible via the Queen's University Belfast Research Portal is retained by the author(s) and / or other copyright owners and it is a condition of accessing these publications that users recognise and abide by the legal requirements associated with these rights.

Take down policy

The Research Portal is Queen's institutional repository that provides access to Queen's research output. Every effort has been made to ensure that content in the Research Portal does not infringe any person's rights, or applicable UK laws. If you discover content in the Research Portal that you believe breaches copyright or violates any law, please contact openaccess@qub.ac.uk. 
Title: What about my voice? Autistic young girls' experiences of mainstream school

Craig Goodall

cgoodall01@qub.ac.uk

Queen's University, Belfast, Northern Ireland

Alison MacKenzie

Queen's University, Belfast, Northern Ireland

Alison.Mackenzie@qub.ac.uk

Corresponding author 


\title{
Title: What about my voice? Autistic young girls' experiences of mainstream school
}

\begin{abstract}
Recognition of inclusion in mainstream schools for all people with disabilities is enshrined in the Convention on the Rights of Persons with Disabilities (CRPD). General Comment 4 onArticle 24 (Right to inclusive education) of the CRPD provides a concept of inclusion and its core features which we discuss here. Article 7 of the same enjoins state parties to give young people's opinions and views 'due weight' on matters that affect them. Despite calls to gather their views on education to better inform policy and practice, autistic young people have been largely missing from the research, girls most notably. Research on the efficacy of mainstream inclusion and the educational experiences of autistic young people has focused mainly on the perspectives of adult stakeholders such as parents, teachers and classroom assistants. Inspired by Article 7 of the CRPD, we present the educational experiences of two teenage girls with Asperger's Syndrome in a mainstream setting in the UK with respect to the school environment, teachers, the curriculum and peers. The findings from semi-structured interviews and a number of participatory methods reveal that girls reported feelings of exclusion, isolation and anxiety. We discuss these findings in the light of the concept of inclusion provided in the General Comment and conclude with the girls' recommendations on how to include people with ASD in mainstream settings.
\end{abstract}

Key words: UNCRPD, inclusion, inclusive education, human rights, autistic girls

\section{Introduction}

The principles of inclusion are driven by equality, social justice and children's rights, involving children learning together so that inclusion is founded upon equity, empowerment, acceptance and belonging. Recognition of inclusion for all people with disabilities is enshrined in the Convention on the Rights of Persons with Disabilities (CRPD. Hereafter, the 'Convention') (2006), the first legally binding instrument which refers to the concept of quality inclusive education. General Comment No. 4 (2016. Hereafter 'GC4') on Article 24 (Right to inclusive education) of the CRPD defines inclusive education as a 'fundamental human right'. It explicitly states that excluding and segregating people from mainstream 
education due to disability (or any other non-moral category), and failing to provide accessible learning environments 'constitute discrimination'.

The CPRD is supported by other internationally recognised human rights instruments. For the last three decades in international human rights law, and of relevance here, children have had the right to express their views on all matters affecting them and to have those views given 'due weight'. This right is enshrined in Article 12(1) of the Convention on the Rights of the Child (CRC) (1989), and in Article 7 of the Convention which further provides that it should be applied equally to children with disabilities. However, that right has rarely been exercised (Lundy 2018). In Northern Ireland, the Special Education Needs and Disability Act (SEND) 2016, Article 1, now emphasises the rights of children to participate in decisions about their education. However, the act makes no provision for support for advocacy of that right, and it is yet to be seen whether children with disabilities will, in fact, have their views given due weight.

Research on the efficacy of mainstream inclusion and the educational experiences of autistic young people, and what is best for improving their educational outcomes, has focused mainly on the perspectives of adult stakeholders such as parents, teachers and classroom assistants. How autistic young people, the focus of interest for this article, conceptualise inclusion, whether or not they are treated with dignity and respect, or have their views heard, seem largely absent from debates on what constitutes quality inclusive education.

More critically with respect to autistic girls, few studies within this limited research have harnessed their views on how they have experienced schools, or how their feedback could help put inclusive values into action. The absence of autistic girls' voices is due, in part, to their underdiagnoses. Subtle gender differences in the characteristics of autistic girls compared to boys, such as fewer unusual stereotypical and repetitive behaviours, may explain this under-identification. In comparison to autistic boys, girls have better expressive behaviours, such as holding reciprocal conversation and better initiation of interactions, giving the illusion that they are coping (Lai et al. 2015).

To contribute to research that avowedly includes the voice of autistic girls, and in spirit with Article 7 of the Convention, we present an in-depth, multi-method, retrospective qualitative account of the educational experiences in a mainstream setting in Northern Ireland of two 
teenage girls with Asperger's Syndrome, 'Ro' and Sarah-Jane'. As they will reveal, mainstream schooling has been very challenging, and their experiences are typical of what is reported elsewhere by autistic young people: exclusion, isolation, anxiety, and unhappiness, experiences and feelings which are not in harmony with the concept of inclusion advanced by the CRPD. As their descriptions will reveal, barriers to inclusion persist for Ro and Sarah-Jane. The girls' experiences offer powerful testimony on the effectiveness of their inclusion when set against the normative content of General Comment No 4 (GC4), Article 24. Here, they offer their conception of inclusion and advice on how to make schools more inclusive than they seem at present.

\section{Normative features of, and barriers to, inclusion}

According to the GC4 (2016) inclusive education is to be understood as a 'fundamental right of all learners' at levels (10a); which values 'the well-being of all students' and 'respects their inherent dignity and autonomy' (b); and is a process of 'continuing and pro-active commitment to eliminate barriers impeding the right to education' (d). Inclusive education is different from integration. Integration is the placing young people with disabilities in mainstream settings on the understanding that they can adjust to the norms and practices of the school (11). Inclusion, on the other hand, is a process that involves:

systemic reform embodying changes and modifications in content, teaching methods, approaches, structures and strategies in education to overcome barriers ... to provide all students ... with an equitable and participatory learning experience and the environment that best corresponds to their requirements and preferences. GC4 11

As GC4 states, placing pupils with disabilities within mainstream classes without changes to, for example, organisation or curriculum and teaching and learning strategies, does not constitute inclusion. An inclusive environment is one which embodies a number of core features. For example: a 'whole systems' approach by which resources should be invested to advance inclusive education (12a); a 'whole person' approach which recognises the capacity of every person to learn (c); respect for and value of diversity (e); and a 'learning friendly environment' where everyone feels safe and valued (f). Teachers, too, should receive education and training to provide them with the values and competencies to 'accommodate inclusive environments' (d). 
However, barriers to inclusion persist. The Northern Ireland Commissioner for Children and Young People (NICCY 2007) commissioned a large review of the needs and services in Northern Ireland and sought the experiences of parents, professionals and children and young people (gender not stated) with Asperger's Syndrome. The barriers to positive school experience included: lack of understanding from staff and pupils, and the unwillingness of staff to accommodate the specific needs of the child. Only $50 \%$ of the young people $(n=35$, aged 10-18) in this study were 'quite' or 'very satisfied' with their school experience, and 57\% want teachers to have greater understanding of Asperger's and provide better support. Further, 66\% would like their school experience to be significantly different, particularly with respect to bullying, and to have safe learning environments. The positive aspects of having Asperger's was primarily to do with intellectual ability: being smart, the ability to concentrate and having a good memory. Currently, despite the provision of Articles 28 (Right to Education) and 29 (Goals of Education) of the CRC which continues to influence education policy and provision in Northern Ireland, neither the Department of Education nor the Education Authority (EA) can demonstrate value for money with respect to 'efficiency or effectiveness in the provision of support to children with SEN in mainstream schools' (NIAO 2017, 4). No mention is made of CRPD.

Other studies reveal similar difficulties elsewhere. Dean et al. (2014) studied the social relationships of elementary school children with high-functioning autism in the USA to explore how gender relates to social connections and reciprocal friendships. Their analysis found that though the social challenges associated with ASD were equally present in both primary school boys $(\mathrm{n}=50)$ and girls $(\mathrm{n}=50)$, autistic boys were more overtly included by peers than were autistic girls; they, by contrast, tended to be overlooked, or even neglected. Both groups, however, had fewer regular friends, and were located on the periphery of social groups to a greater degree than their non-autistic peers.

Moyse and Porter (2015) undertook ethnographic case studies on three autistic girls (aged 711) attending mainstream primary schools in the UK and followed these up with interviews. The girls spoke of the difficulties they had working collaboratively with others and with interacting with peers, particularly in the playground and during unstructured times, difficulties that were mainly due to their not being included by peers. They made social adjustments by trying, for example, to hide and or be discrete, and internalised the difficulties they experienced 
with anxiety. These findings mirror the accounts of the girls in this study. Interestingly, the parents and teachers perspectives of the girls' experiences of school were more positive than that reported by the girls. Moyse and Porter $(2015,198)$ suggest that 'masking behaviours' influence the 'perception that others had of the impact of autism on their lives in school'. Autistic girls are at particular emotional and social risk because of the isolation experienced by being off the social radar and having to continually observe and judge the nuances of social situations (Rose and Rudolph 2006). This is supported by other research, for example, Solomon et al. (2012) using psychopathology measures, that shows that autistic girls have higher reported rates of anxiety and depression compared to autistic boys.

Sproston et al. (2017) interviewed eight autistic girls (aged 12-17) and their parents in England to explore their experiences of mainstream schooling, and alternatives, if any, to mainstream provision. The girls described several aspects of their mainstream education that accord with what Sarah-Jane and Ro describe here, including: inappropriate sensory environments, a lack of staff understanding of their needs and how to support them, and inflexible approaches to their inclusion in class or elsewhere. The girls related how they wanted to belong and spoke of positive experiences with teachers who took an interest in getting to know them. They also expressed their enjoyment of the social aspects of school, even despite the experiences of bullying, isolation and rejection. Among the suggestions to improve their experiences in mainstream settings were that schools should be mindful of the impact of the sensory environment. Teachers and staff who demonstrated flexible and approachable attitudes were considered to be more inclusive than those who did not. As we shall see, these suggestions are not dissimilar to the ones offered by Ro and Sarah-Jane in this study.

\section{Research design}

The methods used and matters to be explored were first considered by a Children's Research Advisory Group (CRAG) consisting of three autistic young people. Semi-structured interviews were conducted with the young people and several participatory activities were included within this schedule. These methods were based on the teaching expertise of one of the authors and their selection was informed by, and compliant with, the Article 7 of the Convention described above. The interview schedule was made available in advance of data collection. To help Sarah-Jane express her views she was offered, and subsequently opted for, an email based 
semi-structured interview format, allowing her processing time which reduced the pressure associated with real time responses.

The participatory methods described here were used to gain 'authentic' knowledge about children's subjective realities (Grover 2004), and to help support the participants in expressing their experiences by providing them appropriate and engaging opportunities in a safe and inclusive environment (Lundy and McEvoy 2012). To maximise research accessibility and ensure children's participatory rights could, following Article 7, be exercised, the participants were offered multiple means of representation 'to access and represent different levels of experience' (Bagnoli 2009, 547). For example, in the Beans and Pots activity, participants chose 'true', 'not true' or 'unsure' in response to 17 statements (see Figure 1) by placing a personalised polystyrene ball in one of three pots. These options were visually supported with thumbs up, thumbs down and a question mark instead of an ' $\mathrm{x}$ ' or a 'tick' to remove any notion that there was a correct answer.

\begin{tabular}{|l|l|}
\hline I enjoy going to school & I have friends at school \\
\hline $\begin{array}{l}\text { I would attend a school for only children } \\
\text { with ASD/autism }\end{array}$ & People notice when I am good at something \\
\hline Teachers like me the way I am & People at school are friendly to me \\
\hline $\begin{array}{l}\text { There is an adult I can talk to if I have } \\
\text { problems }\end{array}$ & Teachers want to support me \\
\hline I wish I was at a different school & Other children like me the way I am \\
\hline I feel different from other children here & I feel happy being at school \\
\hline School makes me feel anxious & I feel scared at school \\
\hline I feel excited going to school & I feel accepted in school \\
\hline I feel included in school & \multicolumn{2}{|l}{} \\
\cline { 1 - 2 } &
\end{tabular}

Figure 1: Beans and Pots activity statements

Diamond ranking, as an interactive research tool, helps young people construct and interpret information (Clark 2012). It is also used in UNICEF's rights respecting schools' programmes (https://www.unicef.org/rightsite/files/standupfinal.pdf). Three diamond ranking activities were developed and used: the first acted as a capacity building exercise to practice using the activity by ranking different foods into levels of preference; the second focused on ranking nine aspects of school which were enabling and supportive of the participants, such as: 'having 
friends at school', 'my teacher understanding me for who I am', 'being able to take breaks when I need them'; and the third sought information on barriers to accessing education in mainstream school. Some of the aspects and features to be ranked, such as 'being bullied' or 'the classroom environment being too noisy and busy', reflected what was reported in the literature. Levels of importance were created that did not rely heavily on degrees of feeling, such as scales ranging from 'strongly agree' to 'strongly disagree', especially as autistic children (as with others) may need some explanation of what different degrees of feeling mean (Honneybourne 2015).

Other methods included 'Good teacher, bad teacher'. Participants were given two generic outlines of a figure and were invited to draw, add words, feelings and descriptions to describe the characteristics of a good and a bad teacher. The activity was used to stimulate discussion and to ask in a child-friendly way to 'describe for me in pictures, in writing, and via your voice what a good teacher looks like', and 'how they act and make you feel?'. Me at School' invited them to produce a drawing of themselves at school (see Figures 2 and 3). The participants were encouraged to add written descriptions and to orally describe the drawing.

The analysis followed an inductive approach to allow 'research findings to emerge from the frequent, dominant or significant themes inherent in raw data, without the restraints imposed by structured methodologies' (Thomas 2006, 238). Drawings and accompanying narratives were analysed from a meaning-making perspective, seeking out recurring themes, rather than being appraised on an aesthetic or cognitive basis. Careful transcription of the interviews enhanced the dependability of analysis (Braun and Clarke 2014), and the data was analysed following Braun and Clarke's (2014) well established six phases of analysis.

To ensure trustworthiness and authenticity, a checklist developed by McMillan and Schumacher (2006) guided this study, including: the use of multi-method strategies to support data triangulation in collection and analysis; presenting verbatim accounts of the girls' experiences; recording precise detailed descriptions; and, carrying out informal accuracy checks out with participants during data collection (participant verification).

Table 1 below provides a key to identifying extracts of data, the activity from which these came and to which participant the data belongs. 


\begin{tabular}{|l|l|}
\hline Code & Meaning \\
\hline I & Semi-structured interview \\
\hline $\mathrm{p}$ & Page number of semi-structured interview transcript \\
\hline $\mathrm{C}$ & $\begin{array}{l}\text { Sheet } \mathrm{C}-\text { 'more children with autism are being made to go to mainstream } \\
\text { school' - what do you think about this? }\end{array}$ \\
\hline D & Sheet D - What does school 'inclusion' mean to you? \\
\hline MeAtSch & Me At School activity \\
\hline MyIdSch & My Ideal School activity \\
\hline GtBt & Good Teacher, Bad Teacher activity \\
\hline SJ & Sarah Jane (SJa indicates transcript 'a' and SJb indicates transcript 'b') \\
\hline Ro & Ro \\
\hline Examples & C/SJ = Sheet C, Sarah-Jane \\
\hline
\end{tabular}

\section{Recruitment and sample size}

The girls were part of a wider study of 12 autistic young people aged 11-17 years: 10 boys (from a total available sample of 17) and the two girls (from a total sample of five) were invited to take part. The pupils attended a special school in which one of the researcher works and a volunteer study hub organised by parents of autistic children and young people. Only two girls consented to take part. 'Sarah-Jane' (aged 17) and 'Ro' (aged 16) both of whom have a diagnosis of Asperger Syndrome. Sarah-Jane has, in addition, auditory processing difficulties and Ro has a diagnosis of ADHD which was not diagnosed until they reached secondary school. Both girls attended mainstream primary and secondary schools, but stopped attending secondary because of the difficulties they experienced. After taking a year out from education, Sarah-Jane started a course at a further education college. Ro is home educated and attends a weekly study hub.

The young people who took part in the study, including Sarah-Jane and Ro, drew upon experiences from multiple educational placements, and, unfortunately, the experiences they 
describe were rarely positive. Sarah-Jane for instance, attended four different primary schools and had two unsuccessful secondary school placements.

Researchers have experienced difficulties in recruiting autistic females and so the low number of female participants is commensurate with historical research on Autism. These difficulties have been attributed to the lower rate of diagnosis of females and because current conceptualisations of autism fail to recognise female-manifestations of autism (Mandy and Lai 2017). Of the small number of research studies in which autistic people do have a voice, there is a high male bias in the resultant understanding because of researchers' own understanding of autism and low female recruitment (Dean, Harwood \& Kasari 2017). The consistent male prevalence bias is 4:1 (Kreiser \& White 2014); the ratio of boys to girls in this sample is representative of what has been found elsewhere: 3.4: 1 in this study in comparison to, for example, 3.8: 1 by the DHSSPSNI (2018). We wish to add to a still small, but growing body of literature focusing specifically on the issues experienced by autistic girls so that their conceptualisation and experiences of autism and inclusion can become mainstream.

\section{Ethical considerations}

Ethical considerations most pertinent to this research were: power relations between the researcher and participant (and the research space); researcher bias; voluntarily participation; informed consent; anonymity; confidentiality and protection from harm.

\section{The educational experiences of Ro and Sarah-Jane}

As we noted above, an inclusive environment is one in which students feel valued, respected, included and listened to. Inclusive education offers 'flexible curricula and teaching and learning methods adapted to different strengths, requirements and learning styles' of the pupil (GC4 12[c]). They are also 'learning-friendly environments' in which everyone feels 'safe, supported, stimulated and able to express themselves' (f); and in which effective measures against bullying are in place (e). Yet barriers to inclusion persist because these conditions and processes are generally not realised, and because knowledge about the nature and advantages of inclusive and quality education is lacking (GC4 4[c]).

Ro and Sarah-Jane described a wide range of educational experiences from across mainstream primary and secondary levels that, in their case, do not accord with the normative ambitions 
of the CPRD and GC4. Both discussed their negative experiences of mainstream education relating to school environment, teachers, the curriculum and peers. Despite attempts to include the girls, to varying degrees these experiences contributed to their feelings of exclusion (Moyse and Porter [2015], Sproston et al [2017]). Both Ro and Sarah-Jane chose 'untrue' to the beans and pots statements 'I enjoy going to school' and 'I feel happy being at school'; and 'true' to the statements 'school makes me feel anxious' and 'I feel scared at school'. When asked to describe their feelings about school both provided intensely negative words. SarahJane said she was 'worried', 'scared', 'angry', 'sad', 'unwanted', 'distressed' and 'humiliated'; while Ro said she was 'nervous', 'embarrassed', 'unwanted', 'excluded', 'scared', 'unwell' and 'bored'.

Impact on wellbeing

Sarah-Jane highlighted the impact mainstream schooling was having on her wellbeing. She referred to the structure and procedure of secondary level education, particularly the need for class changes and negotiating chaotic, noisy corridors in secondary school, all of which she found stressful:

'I am not doing this [secondary school] anymore. I am physically, mentally and emotionally drained ... I am done with this. Talking about it makes me angry... very angry and upset'.

Sarah-Jane also found the large numbers of people and general chaos of a secondary school overwhelming:

I was very stressed trying to cope with the noise, the large class sizes, the constant changing of classrooms.... It was awful moving to the next class. Everyone was coming out and it was just swarmed with people pushing, running, shoving, throwing bottles.

Sarah-Jane placed 'having to be in school all day (9am-3pm)' as the second highest worry about school in the diamond ranking activity. Ro spoke of the despair and dread she felt, and how she tried to avoid the next school day:

The night before school I would put off going to sleep to put off school as much as possible ... staying in bed as long as possible and getting up at the last minute. (I/Ro/p3)

Ro also worried about getting into trouble, getting work done properly or falling behind. She also 'had a huge fear of any kind of repercussion for anything' (I/R/p4). If Ro felt nervous in the morning she could not eat. Because the cafeteria was very busy at break she frequently 
went without eating, and at lunch 'I might eat a bit to show that I was eating, but then I wouldn't eat anything until home. I went through whole days without eating'. Hunger, fear, and despair dominated Ro's school day.

\section{Bullying and friendships}

In the diamond ranking activity both girls chose 'being bullied' as their top worry about mainstream school and spoke readily about these experiences.

I was bullied when I was younger ... verbal physical and there was once ... sexual ... which is bad. It was a pupil. [Short silence and closed body language - squeezing her arms in]. Some bullies followed me to secondary school which made me feel I couldn't answer any questions or talk out ... it wasn't just specific bullies. When I was younger it was as if it was okay for everyone to be like that to me ... you know germs ... if kids have germs ... it was like I had germs and they weren't to go near me. (I/Ro/p4)

The bullying, unsurprisingly, led to feelings of social isolation and loneliness which arose from having no close friends, or having no one to whom to relate despite making efforts to build relationships, findings consonant with research cited here (see NICCY 2007 and Dean et al 2014). In response to the statement 'I have friends in school', Sarah Jane and Ro not only indicated this statement was 'untrue', but also stated that they were not sure what a friend was. The following extracts from Sarah Jane, then Ro describe their experiences of isolation and loneliness:

I found that I had no close friends and no one to talk to. I felt very lonely and often found myself without anyone to play with (I/SJa/p1).

I was isolated and separate, in like a bubble of depression and anxiety ... but, I still felt the centre of attention with others looking at me and judging. (MeAtSch/Ro) 


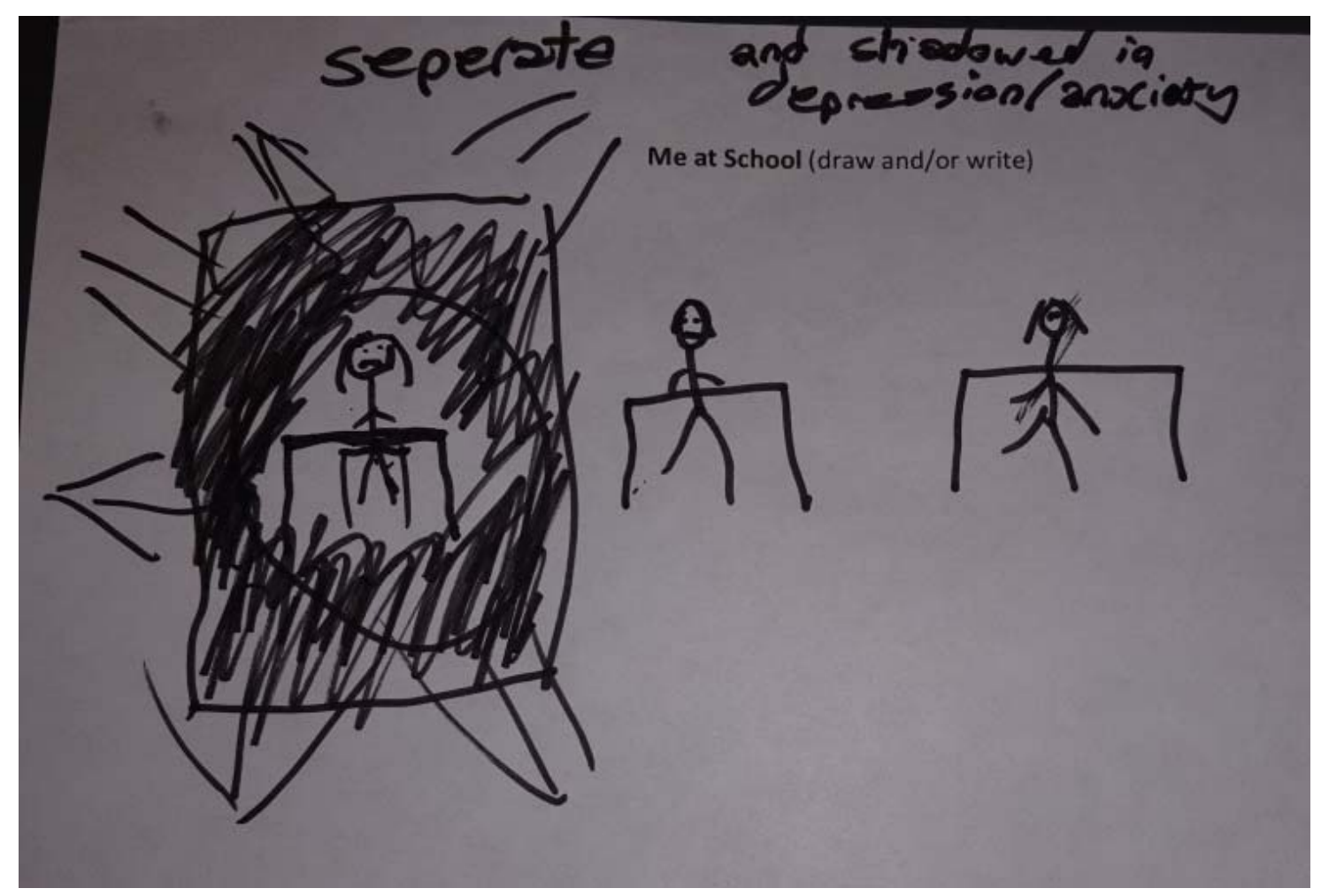

Figure 2: drawing by Ro 'Me at School'.

Sarah-Jane highlighted that peers, as has been reported elsewhere in the literature (Sproston et al 2017), did not wish to befriend her because of judgements about her disability:

It is all about themselves and if you have a disability they do not want to know, they look down at you and think 'no, I am not going to be with her'. (I/SJb/p5)

Sarah-Jane ranked 'having friends at school' as the second most important aspect for making school endurable but has struggled throughout her education to make any. She felt like an 'outsider', someone who did not fit in anywhere with the result that she kept to herself. SarahJane chose 'untrue' to the beans and pots statement 'other children like me the way I am':

I always felt very stressed, anxious and out of place (I/SJa/p2). I felt hurt when excluded by "friends" [she thought they were friends] from joining in with an activity or left out by them when they met up after school without me being invited to join them (I/SJa/p5).

Ro, however, ranked having friends as the least important aspect for making school more enjoyable and supportive for her. In the interviews, Ro said that she was happy spending time alone: I do like my own company as I am quite a solitary person. Although, there were people that I didn't mind being with me. (I/Ro/p6) 
Ro explained that attempts were made by teachers to try and support her in making friends, but no true friendships were formed.

He [a teacher she liked] tried to get other girls to play with me but once that year ended they would stop playing with me. I thought I had made friends (I/Ro/p5).

It may be that over time Ro adapted her expectation downwards in order to avoid the disappointment of not having friends. Ro found the overwhelming nature of the school cafeteria, the social hub of the school, too much. She spoke of the social pressure, the dread of the unknown that she felt at break and lunch times:

The cafeteria ... the noise and business and if you don't have a clique to sit with, people in your class would be like 'what are you doing here?' and it was so full with people. It was a ... mmm ... new piece of pressure each time going in. I went through whole days without eating to avoid it. (I/Ro/p2)

Seemingly harmless classroom approaches can exacerbate feelings of social isolation. For instance, teachers asking pupils to 'find a partner' provided further, more overt, occasions for Sarah Jane to feel isolated and alone:

As usual, I had no one and I was made to pair up with the teacher. I felt so little having to stand there waiting to pair up with the teacher. I had no one. It was awful. (I/SJa/p5)

In response to a question on whether pulling names randomly from a hat would have helped, she replied:

It would have stopped me feeling humiliated and little inside standing there on my own in the classroom. It kind of scars you. Mentally it didn't help me. It was awful being left out and not having a partner to be with. (I/SJb/p10)

Both girls expressed how they felt different from their peers. In the 'beans and pots' activity both chose 'true' to the statement 'I feel different from other children here'. Sarah-Jane expressed how she was judged for having Asperger's, and both stated that the condition makes it hard for them to socialise. Sarah-Jane first:

I find that when people know that I have Asperger's syndrome, they think that I'm stupid. I also feel that I'm judged because of my Asperger's syndrome. I don't like having autism. I think it makes me different to other people and I think other people 
treat me as being different. When I was at school I was often called a geek or weirdo. (I/SJa/p10)

For me autism is something you have ... . If you are blond or brunette ... it is something you live with and deal with. It is a difference. Autism causes me difficulties with socialising and so on. (I/Ro/p8)

\section{Inclusion according to Ro and Sarah-Jane}

Inclusive education is central to achieving high-quality education for all learners (GC4 2016). Inclusive education should empower young people with disabilities by developing life skills, learning and other capacities, human dignity, self-esteem and self-confidence. It also means seeing each person as of equal worth, supporting everyone to feel they belong, and reducing barriers to learning and participation, values enshrined in the Convention on the Rights of the Child (1989), the CPRD (2006) and the GC4 (2016). Inclusion, according to Ro, is 'to be treated as a person'. It is 'a feeling of being happy, welcome and belonging in the environment.

Article 7 of the Convention enjoins state parties to give the opinions of young people due weight on matters that affect them. Sarah-Jane and Ro offered advice on school improvement, what inclusion meant to them and why it was not necessarily happening for many within mainstream schools. They provided powerful insights into the relational aspects of the school macro-system and classroom microsystem that underpin inclusive practice, and which accord with the research findings cited here. GC4 (10[d]) describes inclusive education as 'continuing and pro-active commitment to eliminate barriers impeding the right to education' along with 'changes to culture, policy and practice of schools to accommodate and effectively include all students'. Neither felt included or accepted in school - by peers or teachers, experiences which fall woefully short of the aims and aspirations of the Convention. And neither believed in the efficacy of mainstream schooling for young people with disabilities - at least not while schools are organised as they are at present and are driven by attainment standards. As Sarah-Jane explained 'if the support isn't there in mainstream then it will never be inclusion (D/SJ).

The girls chose 'untrue' to the statements 'I feel included in school' and 'I feel accepted in school'. They place great importance on the school ethos, teacher attitudes, understanding and willingness to support autistic young people, findings that the NICCY reported in 2007. Both stated 'untrue' to the beans and pots statement, 'teachers want to support me', with Sarah-Jane 
choosing 'untrue' for the statement, 'teachers like me the way I am'. Ro stated 'unsure' for this, but added teachers didn't pay enough attention to have an opinion - I was invisible. Ro expands on this:

No one really made any attempt to ask about how I was doing. They [teachers] didn't really notice. As I was quieter they put me with the problem children for group stuff. I didn't talk out much they must have assumed I was okay with it (I/Ro/p2).

The teachers ... as I said didn't ever notice anything or me. (I/Ro/p3)

Sarah Jane, who never felt included in mainstream, reflects on one of her experiences and describes the need for the support to be in place for inclusion to be experienced in mainstream schools:

It takes an awful lot of support and thought from the teacher to make sure children are included. Sometimes the wrong thing is done, such as saying "get a partner ...". Often autistic children don't have anyone to go to so are left alone. (D/SJ)

Sarah Jane also explains that placing all children with autism in mainstream is not a good idea, noting the diversity in learners and the impact of 'forced mainstream school inclusion' may have. To explain why, she drew on her experiences of bullying, peer ignorance about autism, and the lack of teacher support she experienced in mainstream:

Many pupils in mainstream schools don't understand anything about autism. I think it would leave the person with autism open to bullying from their peers and be thought of as some kind of weirdo by the other pupils ... . The idea of someone with autism attending a mainstream school is great if the support is in place for them to be happy and succeed. This may involve adapting the curriculum, i.e. no mental maths or poetry etc., as well as changing how a subject is taught. (C/SJ)

Ro discussed how the ethos of a school must be that which encourages a young person to feel they have something to strive for instead of just feeling that the outcome for participation will be punishment if wrong. She explains:

It is not a matter of bad or good, everything has to be learned and you shouldn't be disciplined for not knowing or not being able to do something. It is about how that mentality is turned around [in schools]. Either you engage and get nothing ... you know there is no reward for engaging, but punishment for getting it wrong. (I/Ro/p8) 
Ro also spoke of wanting teachers to care more about pupils with difficulties rather than focusing only on academic results:

Actually start caring about the students rather than the results they give you. It is about teaching the children and not only caring for the results. Really knowing and paying attention to the children. (I/Ro/p7)

Like Sarah-Jane, Ro never felt included so she found it difficult to define the term. Nonetheless, she offered her thoughts on what inclusion is, who is involved in creating inclusion, and how it makes an included person feel:

I think some teachers think inclusion is 'just ask the pupils a question occasionally' ... it's not that. It is more everyone gets a chance to be involved and have fun.

For Ro, the mentality the teachers and the ethos of the school are fundamentally important, and that the necessary support must be in place for inclusion to truly happen and, critically, to be felt. However, inclusion, according to Ro, does not rely on a particular type of school. For mainstream inclusion to work, autistic young people need to be:

Understood and listened to and rather than them [teachers] just patronising you and telling you to go and sit on your own until you are ok. For me it is just a matter of knowing if your students have problems or not. (C/Ro)

Ro also suggested that as 'long as there are the proper facilities to help with children then it should be ok, but if not it isn't'. (C/Ro)

Ro drew a face and explained that, although it looks 'indifferent', what she wanted to convey was her concern that children with autism would be forced to go to mainstream schools, and experience what she had. Her other-regarding capacity was clearly evident. As is increasingly understood (Lai et al. 2015), autistic girls are more inclined to emotionality and better expressive behaviours than are autistic boys, one reason why they go underdiagnosed. 


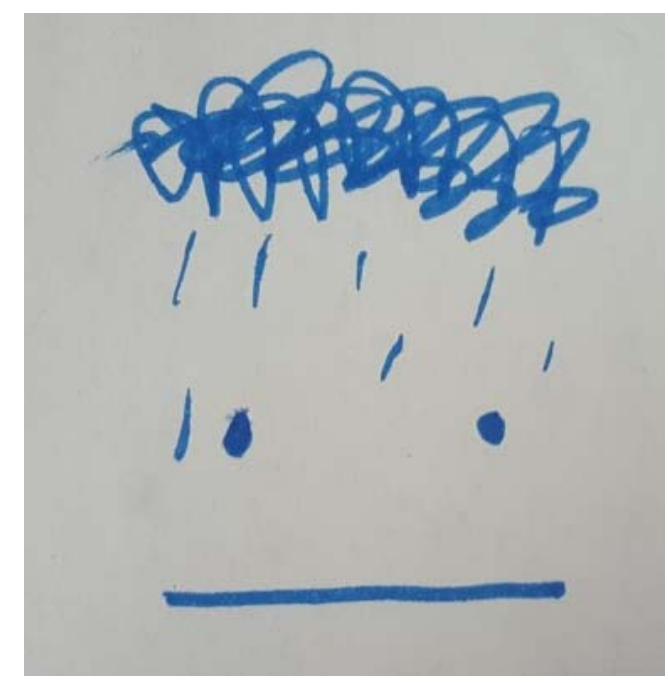

Figure 3: drawing by Ro.

Ro suggests being autism aware and accepting children and young people with autism into school is not enough. As she explains: it's not the building which matters, it's the attitude and atmosphere inside it' (MyIdSch/Ro). Further, in Ro's view, teachers need to be educated about ASD so that they can sensitively support the child. Her analysis offers us further insight into the complexities we face in achieving successful inclusion and meaningful education for these young people: It is a matter of taking the training and using it seriously and understanding that the child is their own person.' (I/Ro/p8)

For both Sarah-Jane and Ro teacher understanding is a key aspect of being a supportive teacher. They judge 'teacher understanding' to be the key attitude that would improve education for them and others, and want teachers to adapt their practice and attitudes to authentically include them. As Sarah-Jane suggests, 'teaching staff might have to re-adjust their thinking and attitudes towards someone with autism and how they can best provide support.' (C/SJ)

\section{Conclusion}

What Sarah-Jane and Ro reveal here was they do not enjoy non-discrimination, empowerment, acceptance or a sense of belonging, features of inclusive environments that, as we suggested earlier, are essential to quality inclusive education and the realisation of the person-centered aspirations of the CPRD and GC4. Inclusion, as a concept, process and a feeling for Sarah-Jane and Ro, is not merely about being in a mainstream school, or exercising the right to be in one. Inclusion means being respected for the persons they are and being valued, despite their 
'oddities' and differences. The two girls demonstrate that the relational aspects of education, being included, feeling a sense of belonging and feeling that they matter as persons, underpins successful inclusion and a meaningful education, and respects their rights. These are insights that are in accordance with human rights protocols on education, the CRC (1989) and the CRPD (2006). Sarah-Jane and Ro also powerfully tell us what it is like to 'feel', to have emotional experiences that, contrary to the stereotype that autistic people are unemotional, can seriously undermine their sense of wellbeing and who they are - or are not - in relation to others. The girls also adopted protective and compensatory behaviours to camouflage their anxiety, despair and isolation by withdrawing from social spaces and activities, and, at the extreme, by avoiding going to school. Such experiences violate their fundamental human right to access and participate in education.

Finally, since this research was carried out with the express intention of hearing and responding to the voices of young people, we here present Sarah-Jane's view on how teachers can improve their relationships with autistic people. A good teacher she told us is: someone who takes time to listen; understands the difficulties and problems that a young person with Asperger's syndrome/autism faces in a school; realises that a person with ASD has sensory issues with noise and crowds, and provides support and help when necessary; realises that it can be difficult for someone with ASD to make friends; ensures that feelings of isolation or anxiety, of not being wanted, are not increased by asking them to choose a partner; provides a quiet area for them to go when they need it; and is 'someone who is patient, kind understanding, helpful, considerate, calm, and above all doesn't shout a lot'. Cognisance of these kinds of views would go a long way to fulfilling the vision of Article 24 of the Convention to develop 'human potential, sense of dignity and self-worth'; and the 'strengthening of respect for human rights, fundamental freedoms and diversity' in our schools.

\section{References}

Bagnoli, A. 2009. 'Beyond the standard interview: the use of graphic elicitation and arts based methods'. Qualitative Research, 9(5): 547-570.

Braun, V. and V. Clarke. 2014. Successful qualitative research: a practical guide for beginners. London: Sage Publications.

Clark, J. 2012. 'Using Diamond Ranking as Visual Cues to Engage Young People in the Research Process'. Qualitative Research Journal 12(2): 222-237 
Dean, M., R. Harwood and C. Kasari 2017. The art of camouflage. Gender differences in the behaviours of girls and boys with autism spectrum disorders. Autism 21(5):678-689.

Dean, M., C. Kasari, W. Shih, F. Frankerl, R. Whitney, R. Landa, C. Lord, F. Orlich, B. King, and R. Harwood. 2014. "The Peer Relationships of Girls with ASD at School: Comparison to Boys and Girls with and without ASD". Journal of Child Psychology and Psychiatry 55 (11): $1218-1225$.

Department of Health, Social Services and Public Safety. 2016. The Prevalence of Autism (including Asperger's Syndrome) in School Age Children in Northern Ireland 2016 DHSSPSNI.

Grover, S. 2004. “'Why Won't They Listen to Us?' On Giving Power and Voice to Children Participating in Social Research'. Childhood 11(1): 81-93.

Honeybourne, V. 2015. Listening to pupils. Special Educational Needs, 74: 58-59.

Lai, M.C., M.V. Lambardo, B. Auyeung, B. Chakrabarti, and S. Baron-Cohen. 2015. "Sex/Gender Differences and Autism". Journal of the American Academy of Child and Adolescent Psychiatry 54(1): 11-24.

Lundy, L. 2018. In defence of tokenism? Children's rights to participate in collective decision making. Human Rights Education Review, 01-24

Lundy, L. and L. McEvoy. 2012. 'Childhood, the United Nations Convention on the Rights of the Child and Research: what constitutes a "rights based' approach?" In Law and Childhood edited by Michael Freeman, 75-91. Oxford: Oxford University Press.

Mandy, W., and M.C. Lai. Towards sex- and gender- informed autism research. Autism, 21(6):643-645

McMillan, J. H. and S. Schumacher. 2006. Research in education: Evidence-Based Inquiry. New York. Pearson Education, Inc.

Moyse, R. and J. Porter. 2015. "The Experience of the Hidden Curriculum for Autistic Girls at Mainstream Primary Schools. European Journal of Special Needs Education 30 (2): 187-201.

Northern Ireland Commissioner for Children and Young People. 2007. "'Try Living in Our World"'. Young people with Asperger syndrome: A review of Needs and Services. NICCY.

Northern Ireland Audit Office (NIAO) 2017. Special Educational Needs. Report by the Comptroller and Auditor General. CDS: Belfast.

Rose, A.J. and K.D. Rudolph. 2006. "A Review of Sex Differences in Peer Relationship Processes: Potential Trade-offs for the Emotional and Behavioural Development of Girls and Boys". Psychological Bulletin 132: 98-131.

Solomon, M., M. Miller, S.L. Taylor, S.P. Hinshaw, and C.S. Carter. 2012. "Autism Symptoms and Internalizing Psychopathology in Girls and Boys with Autism Spectrum Disorders". Journal of Autism and Developmental Disorders 42(1): 48-59. 
Sproston, K., F. Sedgewick and L. Crane. 2017. "Autistic Girls and School Inclusion: Perspectives of Students and their Parents. Autism and Developmental Language Impairments 2: $1-14$.

Thomas, D.R. 2006. 'A general inductive approach to qualitative data analysis'. American Journal of Evaluation 27(2): 237-246.

United Nations 1989. Convention on the Rights of the Child, Office of the High Commissioner, Geneva: United Nations.

United Nations 2006. Convention on the Rights of Persons with Disabilities and Optional Protocol. Office of the High Commissioner, Geneva: United Nations.

United Nations 2016. Convention on the Rights of Persons with Disabilities. General Comment No. 4 (2016) on the Right to Inclusive Education. Geneva: United Nations. 